\title{
Resenha: Corpora no ensino de línguas estrangeiras
}

\section{Cristina Mayer Acunzo*}

VIANA, V. \& TAGNIN, S. E. O. (orgs.). Corpora no ensino de línguas estrangeiras. São Paulo: HUB Editorial, 2011.

Um estudo sobre a presença da Linguística de Corpus no Brasil aponta seu estado ainda jovem, visto que, comparada a outras áreas relacionadas à Linguística, traz um número ainda reduzido de pesquisadores, além do fato de que o primeiro encontro de pesquisadores dessa área interdisciplinar foi realizado em 1999, na Universidade de São Paulo, organizado por Stella Tagnin. ${ }^{1}$ Apesar desse status, é uma área em ebulição, conforme aponta Vera Lúcia Menezes de Oliveira e Paiva no prefácio da obra aqui resenhada, e que já tem disponível diversas produções acadêmicas, corpora e ferramentas disponíveis para pesquisa, como, por exemplo, o corpus do projeto COMET, ${ }^{2}$ que serve de suporte para pesquisas especialmente nas áreas de tradução, terminologia e ensino de línguas, e o CEPRIL, $^{3}$ um portal que oferece ferramentas para análise de corpora que beneficiam tanto estudos de tradução quanto de ensino.

Da mesma maneira que se pode afirmar, como o faz Stella Tagnin na Introdução desta obra, que há 50 anos o professor de línguas - e acrescento, 0 tradutor - não concebesse a possibilidade de analisar grandes quantidade de dados textuais quase que instantaneamente, pode-se dizer que linguistas de

\footnotetext{
* Mestranda em Linguística Aplicada e Estudos da Linguagem pela PUC-SP, bolsista CAPES.

1 Berber Sardinha, T.; Almeida, G. M. B. "A Linguística de corpus no Brasil". In: Tagnin, S. E. O.; VAle, O. A. (orgs.). Avanços da Linguística de corpus no Brasil. São Paulo: Humanitas, 2008.

2 Elaborado junto ao Departamento de Letras Modernas (DLM) da Faculdade de Filosofia, Letras e Ciências Humanas da USP.

${ }^{3}$ Centro de Pesquisa, Recursos e Informação em Linguagem, do PPG do LAEL, da PUC-SP.
} 
Akunzo, C. M.- Resenha: Corpora no ensino de línguas estrangeiras

corpus já não mais se surpreendem ou se apegam a essa questão; a discussão hoje está mais pautada na aplicação das análises e metodologia nas práticas sociais, como no ensino e na tradução.

Corpora no ensino de línguas estrangeiras vem contribuir para a divulgação de pesquisas feitas em Linguística de Corpus, haja vista sua estrutura; a obra traz nove artigos que apresentam estudos voltados para 0 ensino de línguas estrangeiras e de tradução e recebe destaque diante de outras publicações na área por contemplar estudos sobre diversas línguas: inglesa, portuguesa, alemã, francesa e espanhola.

A introdução de Vander Viana e Stella Tagnin resume cada um dos estudos, servindo de guia para o leitor. Cabe também destacar o glossário de Linguística de Corpus e uma compilação de corpora on-line ao final do livro, organizados por Stella Tagnin, de grande valia para pesquisadores, professores e tradutores tanto iniciantes, como experientes.

Salientamos, antes de tudo, que o foco principal da obra é a aplicação de corpora no ensino de línguas estrangeiras; entretanto, o tradutor pode se valer das metodologias usadas e das análises feitas pelos autores para seu conhecimento e pesquisas. Um dos capítulos apresenta especificamente um estudo sobre o ensino de tradução. Optamos, pelo escopo desta revista, por tratar desse artigo anteriormente aos outros e com um enfoque maior, pensando no leitor interessado primordialmente dessa área.

Vander Viana abre a obra com um artigo bastante elucidativo que não somente expõe a Linguística de Corpus ao leitor que a desconhece, demonstrando os procedimentos utilizados nessa área de estudo com o corpus de língua portuguesa Lácio-Ref, ${ }^{4}$ mas também apresenta pesquisas feitas por brasileiros e aplicações pedagógicas desse tipo de investigação. 0 autor parte da fundamentação da Linguística de Corpus, o estudo da língua em uso por meio de dados, explicando e exemplificando de maneira bastante clara e precisa seus conceitos mais pertinentes, quais sejam, corpus, suas

\footnotetext{
${ }^{4}$ Subcorpus do Lácio-Web, disponível em http:// www. nilc.icmc.usp.br/lacioweb/.
} 
Akunzo, C. M.- Resenha: Corpora no ensino de línguas estrangeiras

características, tipos e critérios de coleta; palavra e sua contabilização em um corpus; padrão, colocação, coligação e prosódia semântica; procedimentos e ferramentas de análise, especificamente o programa WordSmith Tools, ${ }^{5}$ haj a vista seu uso por todos os autores do livro; concordanciadores e linhas de concordância. Ao final do artigo, perguntas, seguidas de suas respostas, servem de guia para o professor explorar a língua em uso por meio de corpora.

Uma das grandes dificuldades do tradutor iniciante é a percepção dos aspectos macrotextuais; por muitas vezes desconhecer as convenções das línguas com que trabalha, ele tende a traduzir cada item lexical individualmente, ignorando as unidades fraseológicas, o que pode levar a traduções pouco naturais, que não soam bem ao leitor nativo da língua. Em adição, a tradução pode resultar dessa forma quando as escolhas linguísticas desse tradutor baseiam-se tão-somente nas possibilidades com que se depara, e não na probabilidade linguística. ${ }^{6}$

É justamente nesse ponto que a Linguística de Corpus mostra-se de grande utilidade, visto que proporciona a investigação da língua em textos autênticos por meio de ferramentas que permitem a análise de termos em um corpus paralelo, composto por textos originais e suas respectivas traduções, ou em um corpus comparável, composto por textos similares nas línguas com as quais trabalha o tradutor. ${ }^{7}$

No presente livro, Fabio Alves e Stella Tagnin partem de estudos sobre expertise para a aplicação da prática deliberada com aprendizes de tradução visando uma maior conscientização linguístico-discursiva, desenvolvendo suas características cognitivo-discursivas e dirimindo, assim, suas limitações no

\footnotetext{
5 Programa desenvolvido por Mike Scott, que abre essa obra com um texto sobre Tim J ohns e sua prática na Linguística de corpus, valiosa contribuição para os estudos da área.

6 TAGNIN, S. E. O. Os Corpora: instrumentos de auto-ajuda para o tradutor. Cadernos de Tradução (UFSC), Florianópolis, v. 9, n. 2002/ 1, 2003: 191-213.

7 TAGNIN, S. E. O. A identificação de equivalentes tradutórios em corpora comparáveis. In: I Congresso Internacional da ABRAPUI, 2007.
} 
Akunzo, C. M.- Resenha: Corpora no ensino de línguas estrangeiras

trabalho tradutório. Essa prática consiste na elaboração de um glossário técnico com base em corpus.

Os autores abordam os estudos teóricos que envolvem o conhecimento experto, apontando domínios que o tradutor necessita desenvolver no desempenho cognitivo, assim como a questão da competência tradutória, à qual se pode chegar por meio da prática deliberada, que dá ensejo para tal desenvolvimento. A proposta dessa prática caracteriza-se por tarefas bem definidas e apropriadas aos aprendizes, que proporcionam feedback e, consequentemente, oportunidade para correção, e engloba seis passos para a produção do glossário, quais sejam, a escolha de uma de uma área de especialidade específica; a seleção e a coleta dos corpora e seu balanceamento, por ser comparável e não paralelo; a extração dos candidatos a termos por meio de ferramentas computacionais; a identificação dos equivalentes e a compilação do glossário. Cada um desses passos é bem descrito e exemplificado, de modo que tradutores e professores que atuam na área podem seguir com facilidade e aperfeiçoar suas práticas.

0 artigo ainda traz, para ilustrar a proposta, os resultados de um estudo de caso envolvendo o desenvolvimento da prática deliberada rumo à expertise com dois tradutores que constroem um glossário da área de Química, o qual foi publicado por uma editora comercial. Com base nas respostas dos participantes à atividade e a um questionário, verificou-se que a experiência resultou de tal maneira positiva que a elaboração de corpora e seu uso na tradução foram incorporados pelos mesmos em sua prática profissional, além de ter rendido a publicação. Cabe destacar, ainda, que tal atividade despertou a motivação dos aprendizes por duas razões, ao observarem que 0 uso de corpus facilita o trabalho tradutório com áreas desconhecidas e pela experiência autêntica, visto que o glossário foi submetido a revisões de editor e especialista.

Trata-se, portanto, de um artigo que contribui para a formação de tradutores no que concerne 0 desenvolvimento do comportamento 
Akunzo, C. M.- Resenha: Corpora no ensino de línguas estrangeiras

autorregulatório e a percepção da metacognição, além de elucidar as vantagens da Linguística de Corpus para a Tradução.

No ensino de línguas estrangeiras, geral, para fins específicos ou para negócios, as combinações de itens lexicais, como padrões léxico-gramaticais e colocações, ainda são abordadas de maneira superficial e tradicional, relacionadas ao ensino de gramática, com nenhuma ou pouca contextualização e exploração da língua em uso.

Partindo da constatação em uma pesquisa-piloto de que as colocações adverbiais recebem pouca ou nenhuma atenção em materiais didáticos voltados para o ensino de inglês para negócios, Andréa Geroldo dos Santos faz um levantamento das colocações mais frequentes na área. Para tanto, a autora compila um corpus composto por textos publicados em periódicos e relatórios anuais de empresas, seleciona criteriosamente e analisa oito colocações adverbiais típicas da área, as quais sequer aparecem nos materiais didáticos estudados. O estudo aponta para a importância do ensino dessas colocações, bem como de seu uso, por meio de uma abordagem desvencilhada do aspecto gramatical e mais próxima da convencionalidade e dos aspectos pragmáticos e semânticos para que 0 aprendiz atinja fluência no idioma, utilizando um léxico mais rico e preciso. Destacamos aqui a clareza da autora ao discorrer sobre 0 ensino de inglês como especialidade e sobre a convencionalidade, ainda pouco considerada no ensino.

$\mathrm{Na}$ área e ensino de inglês para fins acadêmicos, Carmen Dayrell traz uma investigação bastante relevante para estudantes de cursos superiores sobre o uso da língua inglesa no que concerne as características gramaticais e lexicais em resumos de artigos científicos (abstracts) escritos por estudantes brasileiros, visto que sua aceitação em eventos internacionais ou até mesmo a leitura de um artigo depende de uma redação eficiente. 0 corpus de resumos escritos por pós-graduandos brasileiros foi comparado a um corpus composto por resumos publicados em periódicos de excelência, ambos nas áreas de Física, Ciências Farmacêuticas e Computação. Os achados dessa comparação motivaram o estudo do uso dos verbos 'present', 'find' e 'show', o que 
Akunzo, C. M. - Resenha: Corpora no ensino de línguas estrangeiras

evidenciou algumas tendências dos alunos como, por exemplo, para o uso de formas impessoais e a pouca familiarização com os padrões léxico-gramaticais formados pelos verbos. A autora, então, exemplifica a aplicação desses resultados no ensino de forma que os aprendizes possam observar e aprimorar o uso desses padrões, tipicamente usados nesse gênero.

Cabe ressaltar que em ambos os estudos a análise dos dados apresentase bastante minuciosa e em concordância com a seriedade dos estudos em Linguística de Corpus no que diz respeito aos aspectos estatísticos e de normalização na análise de dados.

No âmbito do ensino de inglês geral, Marcia Veirano Pinto e Renata Condi de Souza apresentam uma proposta para a exploração da língua em uso por meio de roteiros de filmes comerciais, focando a conscientização dos aprendizes no que concerne a associação das escolhas linguísticas e seus efeitos no contexto de comunicação. Dessa forma, foi compilado um corpus de 72 roteiros e enfatizou-se a análise de 'just', devido a sua alta frequência e disposição no corpus, bem como pelo fato dessa unidade lexical estar, no ensino, comumente relacionada ao seu uso juntamente com o present perfect e muito pouco ou nada ao seu uso pragmático, o qual é mais frequente no corpus estudado. Um ponto interessante da pesquisa é que, além de proporem uma sequência didática, as autoras apresentam os resultados da aplicação da mesma em um curso de aperfeiçoamento, mostrando as respostas dos participantes às atividades de exploração da língua em uso por meio de linhas de concordância e de reflexão sobre as funções pragmáticas de um item lexical.

As aplicações educacionais das três pesquisas são de grande valia para pesquisadores e professores de língua inglesa, que contam com mais recursos para levar à sala de aula o uso mais efetivo do idioma.

0 primeiro artigo sobre a pesquisa em língua estrangeira que não 0 inglês propõe uma metodologia para o ensino de leitura instrumental em alemão para estudantes de graduação, por meio da exploração de um corpus 
Akunzo, C. M. - Resenha: Corpora no ensino de línguas estrangeiras

comparável, composto por artigos de Cardiologia em português e alemão. Maria José Finatto, Leonardo Zilio e Elisandro José Migotto reforçam a validade do uso de corpora no ensino, elucidando as diversas possibilidades de reflexão e aprendizagem que esse tipo de abordagem proporciona, no estudo da estrutura e da terminologia, bem como da macroestrutura e da microestrutura de textos de determinados gênero e área de especialidade.

No âmbito do ensino de francês como língua estrangeira, Adriana Zavaglia e Marion Celli apresentam uma pesquisa que mostra a variação de uso, padrões e sentido de palavras ditas gramaticais no francês e no português - em especial a conjunção 'mas'/ 'mais' - enfatizando o problema de sua tradução sem se considerar o contexto de uso. Expondo ao leitor o panorama histórico do ensino de francês, as autoras apontam as deficiências e contradições da abordagem atual, que se baseia nas propostas do Quadro Europeu Comum de Referência, também muito utilizado no ensino de língua inglesa, visto que desconsidera as teorias de linguagem mais recentes e menospreza os avanços tecnológicos da informática. Diante desse panorama, o artigo contribui com uma abordagem complementar baseada no conceito da transcategorialidade e na Linguística de Corpus, oferecendo exemplos de exercícios para a aplicação da mesma, levando o aprendiz a refletir sobre e construir relações entre sua língua materna e a língua estrangeira.

A Linguística Sistêmico Funcional fundamenta a pesquisa de Adriana Silvina Pagano e Giacomo Patrocínio Figueiredo, que utilizam a Linguística de Corpus como metodologia para a comparação da gramática da dor em português e espanhol. Nos corpora - compostos por entrevistas, textos informativos e fóruns de discussão nas duas línguas - foram analisados os padrões de 'dor' e 'dolor' por meio de linhas de concordância, objetivando verificar os recursos léxico-gramaticais mais utilizados, apontando as diferenças e semelhanças relacionadas aos seus usos e sentidos. Conforme sugerem os autores, ambos professores de línguas e tradutores podem se beneficiar ao seguir esse percurso metodológico; no ensino, essa metodologia proporciona o estudo dos usos da linguagem e a exploração de campos 
Akunzo, C. M.- Resenha: Corpora no ensino de línguas estrangeiras

semânticos específicos; na tradução, por sua vez, proporciona 0 desenvolvimento da habilidade de ressignificação, considerando-se o contexto de uso da língua, ao invés da transferência de significados.

Por fim, o livro traz um artigo de Tony Berber Sardinha, que apresenta dois assuntos, sendo o primeiro a discussão de três propostas de ensino com base em corpora e o segundo um panorama sobre a Linguística de Corpus educacional no Brasil. Após enumerar diversas razões para o uso da abordagem da Linguística de Corpus no ensino, o autor discorre sobre três tipos de atividades que podem ser aplicadas, apontando suas vantagens e desvantagens: (1) centradas na concordância, bastante utilizada desde a década de 90 até os dias atuais; (2) centradas no texto, cujas principais vantagens caem sobre 0 ensino de línguas instrumentais, e (3) multimídia/multigênero, desenvolvida e sugerida pelo autor. Talvez por ser inovadora, essa última proposta resulta bastante atual e contextualizada, tendo em vista que relaciona uma atividade social e os gêneros associados a ela.

Com relação à Linguística de Corpus educacional, é apresentado um levantamento da sua produção e atuação nos últimos dez anos e de seus problemas, como a escassez de praticantes e a pouca presença em cursos superiores, o que acarreta a dificuldade em conseguir financiamento para projetos e falta de doutores na área.

Acreditamos que essas questões também se apliquem na vertente da tradução e pesquisadores tanto do ensino, como da tradução podem refletir sobre esse panorama, sobre as soluções sugeridas pelo autor e sugerir suas próprias para os problemas enfrentados e ampliar a atuação da Linguística de Corpus no país. 